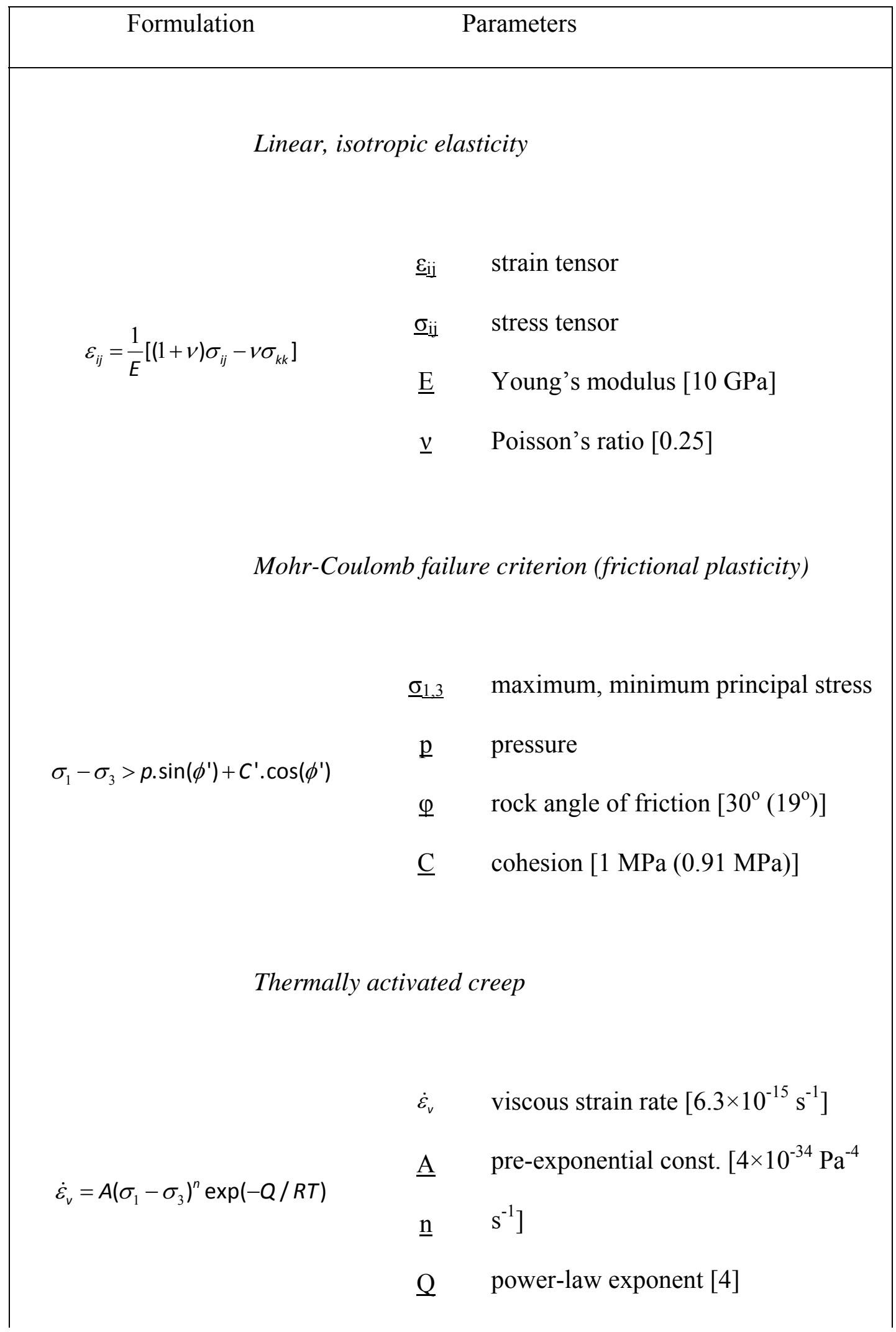




$$
\begin{array}{ll}
\underline{\mathrm{R}} & \text { activation energy }\left[135 \mathrm{~kJ} \mathrm{~mol}^{-1}\right] \\
\underline{\mathrm{T}} & \text { gas constant }[8.314] \\
& \text { temperature }
\end{array}
$$

\section{Fault friction}

$\underline{\tau} \quad$ fault shear stress

$\tau>\mu_{d} \sigma_{n}$

$\underline{\mu}_{\mathrm{d}} \quad$ dynamic friction coefficient [0.2]

$\underline{\sigma}_{n} \quad$ fault normal stress

Other

$$
\begin{array}{ll}
\varrho & \text { density }\left[2800 \mathrm{~kg} \mathrm{~m}^{-3}\right] \\
\mathrm{g} & \text { gravity }\left[9.81 \mathrm{~m} \mathrm{~s}^{-2}\right]
\end{array}
$$

Table DR1: Summary of model methods and rheologies. Prescribed parameter values given in brackets. Note that we have used adjusted values (in parentheses) for rock angle of friction, $\varphi^{\prime}$, and cohesion, $\underline{C^{\prime}}$. These values reflect the reduced strength of a crust saturated by pore fluids at hydrostatic pressure. Parameters for thermally activated creep are derived from Paterson and Luan (1990).

\section{REFERENCES CITED}


Paterson, M. S., and Luan, F. S., 1990, Quartzite rheology under geological conditions, in Knipe, R. J., and Rutter, E. H., eds., Deformation Mechanisms, Rheology and Tectonics, Geological Society Special Publications, v. 54, p. 299-307. 